\title{
Análise dos impactos ambientais da Urbanização sobre os recursos hídricos na sub-bacia do Córrego Vargem Grande em Montes Claros-MG
}

\author{
Analysis of the environmental impacts of urbanization on water resources in the sub - \\ basin Stream Vargem Grande in Montes Claros -MG
}

Renato Ferreira da Silva

Geógrafo, Especialista em Meio Ambiente e Desenvolvimento Regional, UNIMONTES, MG, Brasil

renato.ferreiradasilva@yahoo.com.br

Vanderson Aguiar Santos

Engenheiro Civil, Especialista em Saneamento e Meio Ambiente, Faculdades Pitágoras, Brasil vanderson@seamengenharia.com.br

Sanndy Maria Gonçalves Galdino Geógrafa, UNIMONTES, Brasil sanndygoncalves@yahoo.com.br

\begin{abstract}
Resumo
O presente estudo trata do diagnóstico da influência do crescimento urbano na área da sub-bacia hidrográfica do rio Vargem Grande em Montes Claros-MG e os impactos ambientais que esse crescimento causa nos recursos hídricos. As análises feitas revelaram que o rápido crescimento da mancha urbano tem proporcionado o comprometimento da quantidade e qualidade da água dessa sub-bacia através de atividades antrópicas realizadas no local como: loteamentos urbanos, retirada da vegetação natural além de lançamento de resíduos sólidos nos cursos d'água ou próximo a eles.
\end{abstract}

Palavras-chave:Recursos Hídricos, Crescimento Urbano, Impactos Ambientais.

\begin{abstract}
This study deals with the diagnosis of the influence of urban growth in the area of the sub-basin of the river Vargem Grande Claros -MG Montes and environmental impacts that this growth because water resources. The analyzes revealed that the rapid growth of urban spot has provided the commitment of the quantity and quality of water in this sub -basin through anthropogenic activities on site as urban settlements, removal of natural vegetation as well as release of solid waste in watercourses ' water or close to them.
\end{abstract}

Keywords: Water Resources, Urban Growth, Environmental Impacts. 


\title{
1. INTRODUÇÃO
}

Analisar impactos ambientais em áreas urbanas torna-se fundamental para o planejamento, desenvolvimento e ordenamento das cidades, a necessidade de desenvolvimento da sociedade propõe um modelo de apropriação do espaço geográfico através da utilização principalmente de seus recursos naturais.

Baseado nesse modelo de desenvolvimento observa-se principalmente nas cidades a crescente demanda por recursos naturais e espaço físico, com isso áreas que deveriam servir como suporte à preservação ambiental como as margens de córregos e rios (Áreas de Preservação Permanente - APP) passam a serem ocupadas de forma desordenada e sem planejamento, o que acarreta em diversos problemas ambientais urbanos como inundações, proliferação de doenças veiculadas a água, despejo de efluentes sanitários nos corpos hídricos, deslizamentos de terra, enchentes, aumento do escoamento superficial, dentre outros.

Diante disso Almeida et.al (2010) expõem:

\begin{abstract}
Os impactos ambientais decorrentes das ações antrópicas podem determinar o desequilíbrio no sistema, desestabilizando o meio ambiente. A amplitude dessa desestabilização depende do grau de interferência que o meio sofre. Em se tratando de bacia hidrográfica, seja de grande ou pequeno porte não é diferente, pois, os cursos da água natural e toda a unidade fisiográfica da área de sua abrangência têm representatividade essencial para a vida silvestre (ALMEIDA et.al, p.2, 2010)
\end{abstract}

Os impactos nos recursos hídricos urbanos são invariavelmente ocasionados pelo desenvolvimento dos centros urbanos, e a ocupação da bacia hidrográfica segundo Tucci (2005), tende a ocorrer de jusante para montante, devido às características do relevo. No caso da cidade de Montes Claros o processo de urbanização se deu a partir da década de 1970 com a chegada da Superintendência de Desenvolvimento do Nordeste (SUDENE) que subsidiou os principais investimentos industriais no Norte de Minas nesse período.

O processo de industrialização em Montes Claros transformou profundamente o espaço urbano local, de acordo com Leite e Pereira (2008) citados por Ribeiro et al. (2010) "na década de 1960 a população era estimada em 50 mil habitantes, enquanto em 1980 esse numero já era de 150 mil habitantes, ou seja, mais de $200 \%$ em vinte anos".

O crescimento populacional urbano abrupto trouxe consigo a falta de organização do espaço urbano de forma adequada por parte do poder público municipal. Com isso as margens do Rio Vieira e de seus principais afluentes foram ocupadas, fato que colaborou diretamente para execução de ações como encaixotamento dos córregos, impermeabilização do solo através de massa asfáltica na pavimentação das ruas, além da redução de vegetação natural, o que alterou as características naturais de drenagem das sub-bacias do Rio Vieira, como infiltração e escoamento superficial. Tais 
alterações têm como consequências os impactos diretos sobre a população residente da área com a ocorrência recorrente de enchentes e alagamentos durante o período chuvoso.

Neste contexto, as bacias hidrográficas assumem importante papel no planejamento e gestão ambiental, porque todos os fatores que afetam a produção e o equilíbrio no meio ambiente refletem sobre suas características físicas, bióticas e antrópicas (RESCK, 1992).

A sub-bacia do Rio Vargem Grande foi escolhida como objeto de estudo, por ser uma bacia já urbanizada quase em sua totalidade e que os impactos decorrentes da ocupação tornaram-se mais visíveis devido às inundações ocorridas nos últimos anos, além de ter se tornado local de despejo de resíduos sólidos da construção civil.

\section{CARACTERIZAÇÃo dA ÁREA DE ESTUdO}

A cidade de Montes Claros está localizada no Norte de Minas nas coordenadas: latitude $16^{\circ}$ 44' 13' 'S e longitude $43^{\circ} 51^{\prime}$ '53' 'W, é o principal centro urbano do norte do Estado, possui população de 361.915 (IBGE, 2010).

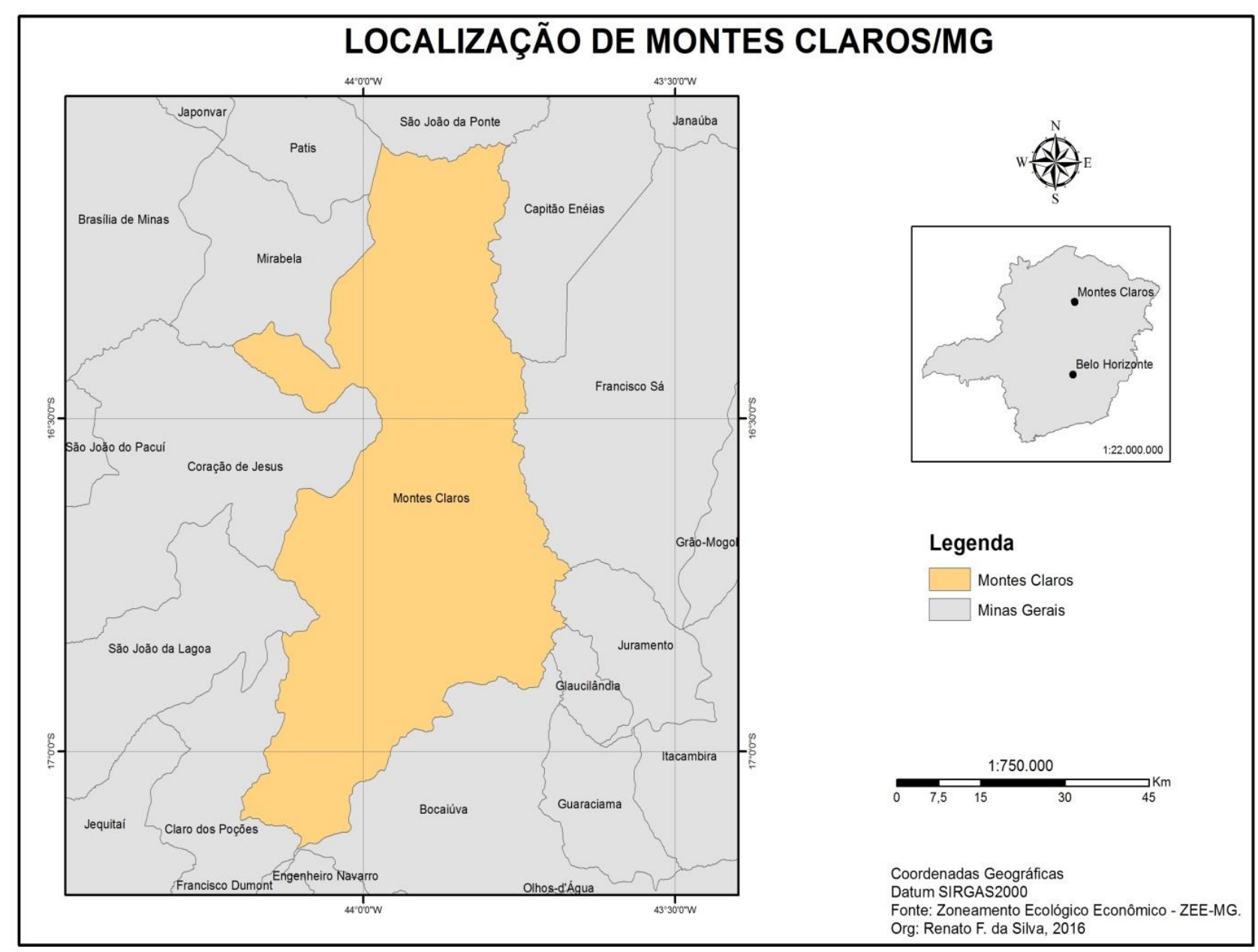

Figura 1 - Mapa de Localização do município de Montes Claros Fonte: Renato Ferreira da Silva, 2016. 
O perímetro urbano está situado na Bacia do Rio Vieira, rio esse que corta a cidade no sentido sul-nordeste. A bacia possui área total de $578 \mathrm{Km}^{2}$. Já a sub-bacia do córrego Vargem Grande é composta pelos córregos Bicano, dos Mangues e Vargem Grande, perfaz uma área total de $18 \mathrm{~km}^{2}$, está localizada a porção sul da cidade de Montes Claros e abrange 36 bairros.

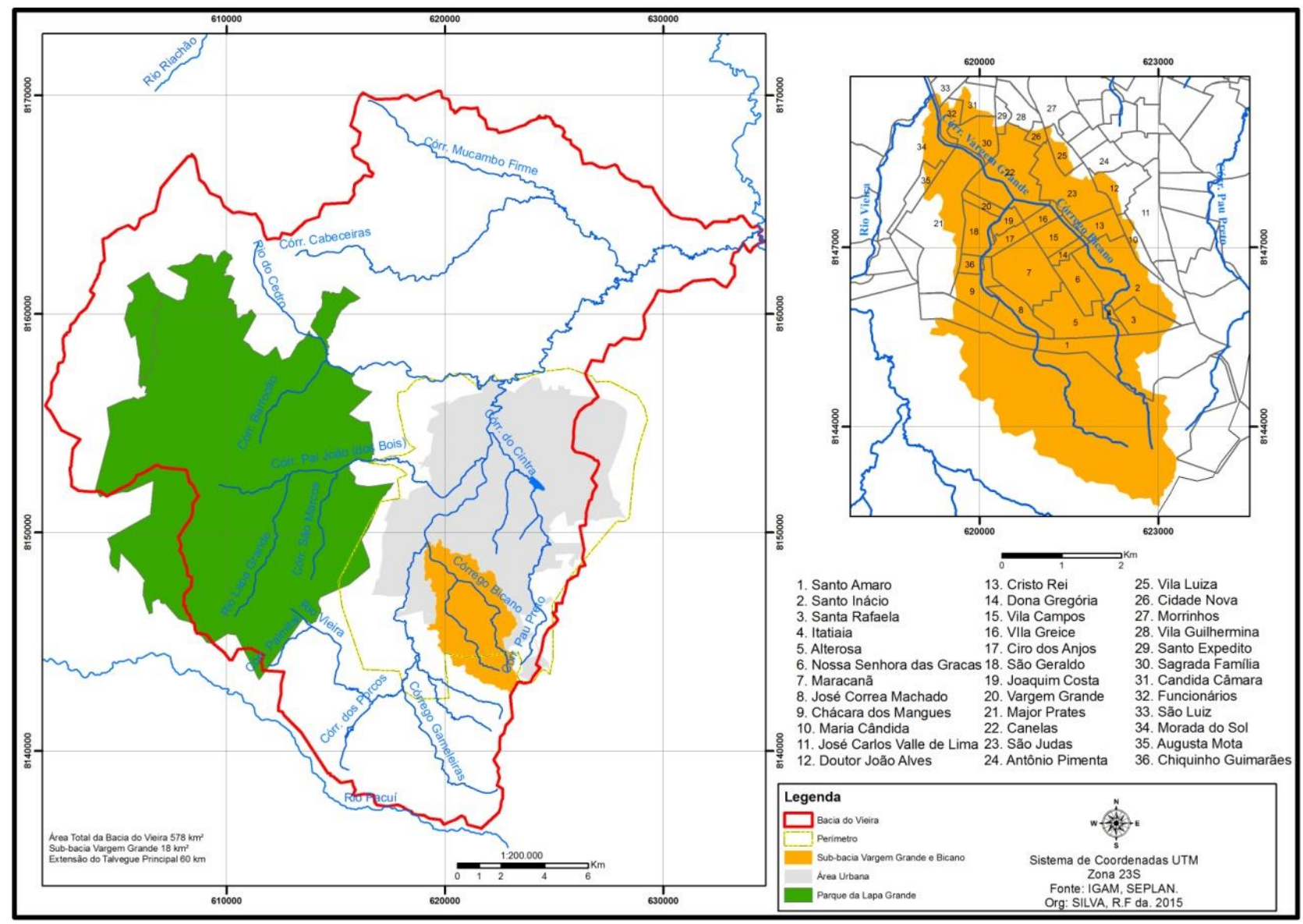

Figura 2 - Mapa de Localização Bacia do Córrego Vargem Grande Fonte: Renato Ferreira da Silva, 2016.

A sub-bacia do Córrego Vargem Grande sofreu impactos significativos oriundos do aumento do processo de ocupação urbana nos últimos anos, sendo os loteamentos urbanos a montante da bacia um dos principais responsáveis pela remoção de vegetação e aumento do escoamento das águas pluviais a jusante.

O encaixotamento do córrego Vargem Grande e do Bicano foi necessário para a implantação de infraestrutura urbana como a criação e pavimentação da Avenida Afonso Guimarães, porém tal medida limita o córrego no período de cheia a um determinado volume de escoamento que tem sua situação agravada graças ao aumento do escoamento superficial e a impermeabilização do solo da bacia, sendo os impactos visíveis através dos fenômenos de enchentes, inundações e alagamentos. Tais impactos trazem transtornos de toda ordem à população. 


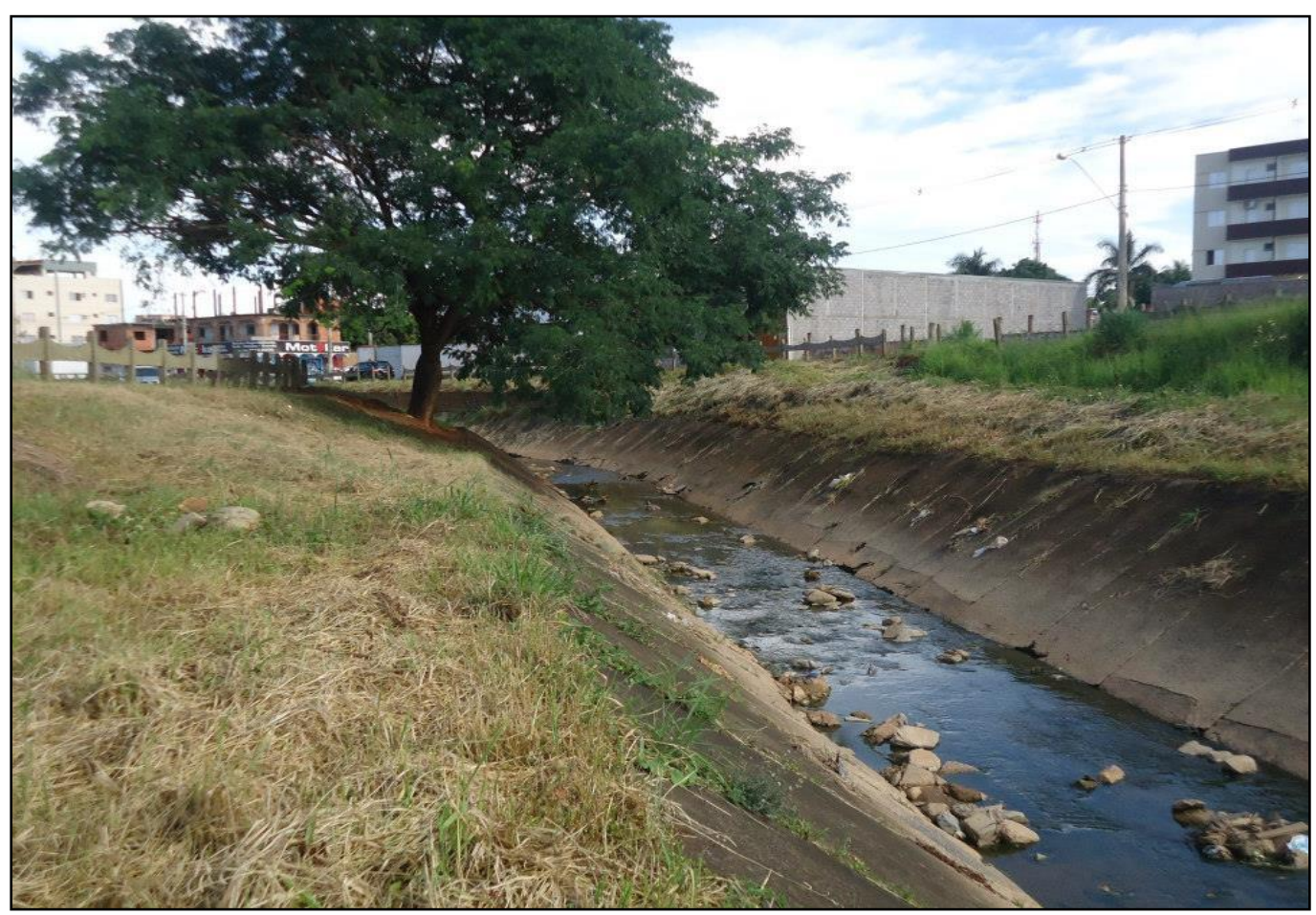

Figura 3 - Córrego Vargem Grande trecho da Avenida Professor Vicente Guimarães. Fonte: Renato Ferreira da Silva, 2015.

As ocorrências de alagamentos as margens do córrego Vargem Grande são agravadas pelo aumento da urbanização, que se materializa através da ocupação residencial e provimentos de novos arruamentos, fato que colabora diretamente para impermeabilização do solo, que dificulta a infiltração natural das águas pluviais e facilita o escoamento superficial concentrado gerando efeito runoff.

Além dessas ações simultâneas e complementares, a bacia do Córrego Vargem Grande sofre com um "estrangulamento" na sua porção mais baixa do relevo caracterizada pela ponte das Avenidas Mestra Fininha e José Correa Machado. No período chuvoso há aumento significativo do volume escoado pelo canal, a sessão fluvial tem seu escoamento limitado á altura da ponte sobre o córrego e a largura do canal. Essas condições fazem com que o volume escoado dentro do canal seja maior do que o suportado pelo espaço sobre a ponte, fato que restringe o escoamento e contribui para o extravasamento das águas gerando inundações e posteriormente alagamentos.

\section{MATERIAIS E MÉTODOS}

Primeiramente foi realizado levantamento bibliográfico acerca principalmente de impactos em bacias urbanas, posteriormente foi gerada a sub-bacia hidrográfica do córrego Vargem Grande por sensoriamento remoto através da imagem de radar do sensor Shuttle Radar Thematic Mapper (SRTM) disponível no sitio da Embrapa Relevo, foi utilizada a carta SE-23-X-A que possui escala de 1:250.000, seguindo utilizou-se o Software Arcgis 9.3 para calcular os fluxos de acumulação e 
direção da drenagem do terreno, aliou-se ao procedimento um ponto coletado por receptor GPS da foz da sub-bacia o que auxiliou na delimitação da bacia hidrográfica a ser estudada.

Por fim como metodologia de avaliação de impactos nos recursos hídricos da sub-bacia do córrego Vargem Grande será utilizada uma Matriz de Impactos, metodologia essa proposta por Leopold (1971) onde as informações são dispostas em linhas e colunas. As matrizes proporcionam uma interpretação multidisciplinar, se caracterizam basicamente pela relação entre impactos identificados com os meios impactados: antrópico, físico e biológico (OLIVEIRA; MEDEIROS, 2007).

A Matriz de Impactos, ou Matriz de Correlação Causa x Efeito, foi inicialmente proposta por LEOPOLD (1971), e vem sendo alterada e aperfeiçoada, como intuito de melhor adequá-la aos objetivos do Estudo de Impacto Ambiental (MOTA e AQUINO, p.1, 2002).

Cada célula matricial é dividida em quatro quadrículas, para valoração dos atributos Caráter, Magnitude, Importância e Duração - do impacto considerado, que serão apostos nas células onde o cruzamento das ações da área estudada produza ou tenha possibilidade de produzir impactos sobre os componentes ambientais, quer sejam impactados ou mostrem susceptibilidade a impactos. O quadro 1 (ANEXO) apresenta o conceito dos atributos aqui utilizados para a caracterização dos impactos, assim como a definição dos parâmetros usados para valoração destes atributos.

Quadro 1 - Atributos de valoração dos impactos

\begin{tabular}{|c|c|c|}
\hline Atributos & Parâmetro de Avaliação & Símbolo \\
\hline \multirow{3}{*}{$\begin{array}{l}\text { Caráter } \\
\text { Expressa a alteração ou modificação gerada por } \\
\text { uma Ação do empreendimento sobre um dado } \\
\text { componente ou fator ambiental por ela afetado. }\end{array}$} & $\begin{array}{l}\text { Benéfico } \\
\text { Quando o efeito gerado for positivo para o fator } \\
\text { ambiental considerado. }\end{array}$ & + \\
\hline & $\begin{array}{l}\text { Adverso } \\
\text { Quando o efeito gerado for negativo para o fator } \\
\text { ambiental considerado. }\end{array}$ & - \\
\hline & $\begin{array}{l}\text { Indefinido } \\
\text { Quando o efeito esperado pode assumir caráter adverso } \\
\text { ou benéfico, dependendo dos métodos utilizados na } \\
\text { execução da ação impactante, ou ainda da interferência } \\
\text { de fatores desconhecidos ou não definidos. Os impactos } \\
\text { indefinidos passam a assumir o caráter benéfico ou } \\
\text { adverso mediante monitoramento ambiental. }\end{array}$ & \pm \\
\hline \multirow{3}{*}{$\begin{array}{l}\text { Magnitude } \\
\text { Expressa a extensão do impacto, na medida em } \\
\text { que se atribui uma valoração gradual às } \\
\text { variações que as ações poderão produzir num } \\
\text { dado componente ou fator ambiental por ela } \\
\text { afetado. A magnitude pode ser definida também } \\
\text { como a grandeza do impacto em termos } \\
\text { absolutos, mensurada quantitativa e } \\
\text { qualitativamente devido a mudança de um fator } \\
\text { ambiental provocado por uma ação. }\end{array}$} & $\begin{array}{l}\text { Pequena } \\
\text { Quando a variação no valor dos indicadores for } \\
\text { inexpressiva, inalterando o fator ambiental considerado. }\end{array}$ & $\mathbf{P}$ \\
\hline & $\begin{array}{l}\text { Média } \\
\text { Quando a variação no valor dos indicadores for } \\
\text { expressiva, porém sem alcance para descaracterizar o } \\
\text { fator ambiental considerado. }\end{array}$ & $\mathbf{M}$ \\
\hline & $\begin{array}{l}\text { Grande } \\
\text { Quando a variações no valor dos indicadores for de tal } \\
\text { ordem que possa levar à descaracterização do fator } \\
\text { ambiental considerado. }\end{array}$ & $\mathbf{G}$ \\
\hline
\end{tabular}




\begin{tabular}{|c|c|c|}
\hline \multirow{3}{*}{$\begin{array}{l}\text { Importância } \\
\text { Estabelece a significância ou o quanto cada } \\
\text { impacto é importante na sua relação de } \\
\text { interferência com o meio ambiente, e quando } \\
\text { comparado a outros impactos. }\end{array}$} & $\begin{array}{l}\text { Não Significativa } \\
\text { A intensidade da interferência do impacto sobre o meio } \\
\text { ambiente e em relação aos demais impactos, não implica } \\
\text { na alteração da qualidade de vida. }\end{array}$ & 1 \\
\hline & $\begin{array}{l}\text { Moderada } \\
\text { A intensidade do impacto sobre o meio ambiente e em } \\
\text { relação aos outros impactos, assume dimensões } \\
\text { recuperáveis, quando adverso, para a queda da } \\
\text { qualidade de vida, ou assume melhoria da qualidade de } \\
\text { vida, quando benéfico. }\end{array}$ & 2 \\
\hline & $\begin{array}{l}\text { Significativa } \\
\text { A intensidade da interferência do impacto sobre o meio } \\
\text { ambiente e junto aos demais impactos, acarreta como } \\
\text { resposta, perda quando adverso, ou ganho quando } \\
\text { benéfico, sobre a qualidade de vida. }\end{array}$ & 3 \\
\hline \multirow{3}{*}{$\begin{array}{l}\text { Duração } \\
\text { É o registro de tempo de permanência do } \\
\text { impacto após concluída a ação que o gerou. }\end{array}$} & $\begin{array}{l}\text { Curta } \\
\text { Existe a possibilidade da reversão das condições } \\
\text { ambientais anteriores à ação, num breve período de } \\
\text { tempo, ou seja, que imediatamente após a conclusão da } \\
\text { ação, haja a neutralização do impacto por ela gerado. }\end{array}$ & 4 \\
\hline & $\begin{array}{l}\text { Média } \\
\text { É necessário decorrer certo período de tempo para que o } \\
\text { impacto gerado pela ação seja minimizado ou } \\
\text { neutralizado. }\end{array}$ & 5 \\
\hline & $\begin{array}{l}\text { Longa } \\
\text { Registra-se um longo período de tempo para a } \\
\text { permanência do impacto, após a conclusão da ação que } \\
\text { o gerou. Neste grau serão também incluídos aqueles } \\
\text { impactos cujo tempo de permanência, após a conclusão } \\
\text { da ação geradora, assume um caráter definitivo, ou seja, } \\
\text { os impactos irreversíveis. }\end{array}$ & 6 \\
\hline
\end{tabular}

\section{IMPACTOS NOS RECURSOS HÍDRICOS}

Qualquer grande alteração em uma bacia hidrográfica, seja em sua estrutura de relevo seja no uso e ocupação do solo, tende a desencadear impactos diretos sobre os recursos hídricos a jusante caso não haja medidas preventivas e corretivas para se evitar tal cenário.

O uso da água pela população e a devolução do recurso sem tratamento para os rios gera uma situação de poluição através principalmente dos efluentes sanitários, que inviabiliza a utilização do recurso nos canais fluviais dos centros urbanos (TUCCI, 1997).

Em relação aos impactos gerados nos recursos hídricos Tucci expõe:

A urbanização também aumenta as áreas impermeáveis e a canalização, o que aumenta os picos de cheia e sua frequiência para a mesma precipitação. A urbanização também aumenta a velocidade da água e a produção de sedimentos e dos resíduos sólidos que escoam para a drenagem (TUCCI, p 117, 1997) 
Outro fator que contribui para a geração de impactos na bacia é a falta de serviços de limpeza e manutenção nos dispositivos de drenagem, como bocas de lobo e bueiros. Com o aumento do volume escoado superficialmente há também o aumento na energia de transporte dos materiais sólidos e impurezas das superfícies urbanas, essa situação contribui para a ineficiência do sistema de drenagem.

O ciclo hidrológico de uma bacia é alterado graças ao desenvolvimento urbano que provoca a supressão da vegetação nativa e implementação de medidas que favoreçam o escoamento direto para o talvegue principal, dentre essa alterações hidrológicas Tucci (1999) destaca:

- Redução da infiltração no solo, O volume que deixa de infiltrar fica na superfície, aumentando o escoamento superficial. Além disso, como foram construídos condutos pluviais para o escoamento superficial, tornando-o mais rápido, ocorre redução do tempo de deslocamento. Desta forma as vazões máximas também aumentam, antecipando seus picos no tempo

- Com a redução da infiltração, o aquífero tende a diminuir o nível do lençol freático por falta de alimentação (principalmente quando a área urbana é muito extensa), reduzindo o escoamento subterrâneo. As redes de abastecimento e cloacal possuem vazamentos que podem alimentar o aquíferos, tendo efeito inverso do mencionado

- Devido à substituição da cobertura natural ocorre uma redução da evapotranspiração, já que a superfície urbana não retém água como a cobertura vegetal e não permite a evapotranspiração das folhagens e do solo

Dentre os fenômenos e impactos mais recorrentes nos recursos hídricos, podem-se destacar alguns enquanto os mais recorrentes.

Inundações são decorrentes de modificações do uso do solo e podem provocar grandes danos, enchentes referem-se à ocorrência natural, normalmente não afeta diretamente a população e tem característica cíclica, as duas ocorrem próximo de cursos d’água. Existem também alagamentos, que ocorrem em consequência da chuva em lugares distantes de curso d'água (CANDIDO, 2007).

Segundo Tucci (1997) existem princípios básicos do controle de enchentes tanto em áreas naturais de várzea como em áreas urbanizadas.

Esses princípios devem primeiramente contemplar as bacias hidrográficas enquanto sistemas, um mecanismo eficaz para a mitigação ou minimização dos impactos nos recursos hídricos seria a implantação de um Plano de Controle de Enchentes ou de Drenagem Pluvial para as cidades, que abarcaria medidas estruturais e não estruturais no conjunto da bacia além de gerenciar o crescimento do horizonte de expansão da cidade, uma vez que depois de ocupada (a bacia) total 
ou parcialmente dificilmente o poder público conseguirá responsabilizar aqueles que ampliam os efeitos das cheias.

Outra medida capaz de contribuir para o gerenciamento de bacias hidrográficas é o Zoneamento, que apresentaria como produto um mapa de inundação composto de linhas que indicam as áreas atingidas para um determinado risco de inundação. A quantificação dos impactos da urbanização sobre o escoamento é imprescindível para que se possa planejar o desenvolvimento urbano (TUCCI, 2005).

\section{RESULTADOS}

Diversos impactos podem ser observados na sub-bacia do rio Vargem Grande oriundos do processo de ocupação urbana ocorrido de forma acelerada Segundo a resolução CONAMA $n^{\circ}$. 001/86 art. $1^{\circ}$ pode-se definir:

(...) impacto ambiental como sendo qualquer alteração das propriedades físicas, químicas e biológicas do meio ambiente, causada por qualquer forma de matéria ou energia resultante das atividades humanas que direta ou indiretamente, afetam: I - a saúde, a segurança e o bem-estar da população; II - as atividades sociais e econômicas; III - a biota; IV - as condições estéticas e sanitárias do meio ambiente; $\mathrm{V}-$ a qualidade dos recursos ambientais.

Dentre os impactos ambientais identificados estão a ocupação nas áreas de montante o que pode comprometer a qualidade e a quantidade de água produzida por essa bacia, os loteamentos feitos nas proximidades do rio Vargem Grande também se tornou um fator preocupante devido a retirada de vegetação natural o que conseqüentemente irá interferir nas características naturais de drenagem como infiltração e escoamento superficial e trará conseqüências para a população residente nessas áreas como as inundações que vem ocorrendo constantemente nos períodos chuvosos.

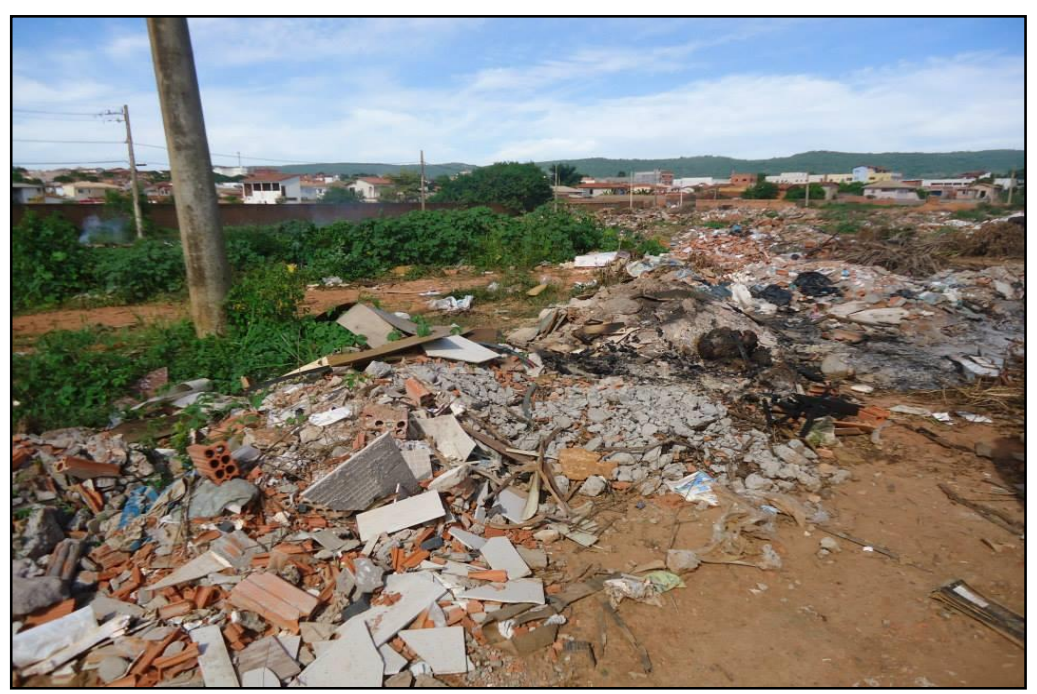

Figura 4 - Córrego Vargem Grande trecho a montante da Avenida Professor Vicente Guimarães.

Fonte: Renato Ferreira da Silva, 2015. 
Além disso, as áreas onde deveriam estar ocupadas pelas matas ciliares estão dando lugar a depósitos de resíduos sólidos provenientes da construção civil interferindo assim de forma direta no regime do ciclo hidrológico o que comprometerá o equilíbrio do microclima da região. Para a mensuração dos impactos e identificação das respectivas atividades geradoras na bacia do Vargem foi elaborada Matriz de impactos (ANEXO).

\section{RESULTADOS E CONCLUSÃO}

Pode-se concluir que o processo de urbanização na cidade de Montes Claros/MG se deu a partir da década de 1970 com a chegada da Superintendência de Desenvolvimento do Nordeste (SUDENE) responsável por subsidiar os investimentos industriais na região, fato que provocou um crescimento populacional acelerado e vários problemas ambientais ocasionados através do uso e ocupação do solo de forma inadequada e planejamento limitado ou até mesmo a falta deste. Como resultado desse cenário temos os processos que ocorrem às margens do Rio Vieira e seus principais afluentes que resultam no comprometimento da qualidade e quantidade da água produzida por essa bacia, desequilíbrio do ciclo hidrológico, alteração do microclima regional, além de consequências para a população residente nas proximidades como as enchentes ocasionadas em períodos de chuvas intensas.

Dessa forma torna se necessário um planejamento adequado e eficaz nas cidades, que garantam a todos os cidadãos uma qualidade de vida satisfatória. Portanto deve-se aliar o planejamento urbano, ao planejamento e a gestão ambiental, realizando de forma consciente medidas preventivas e corretivas para evitar os impactos nos recursos naturais.

\section{REFERÊNCIAS}

ALMEIDA, J.W.L (et.al). Geotecnologias aplicadas ao uso do solo: Estudo de Caso da bacia do Vieira no município de Montes Claros-MG. Anais XVI Encontro Nacional de Geógrafos. Porto Alegre, 2010.

CASSOL, P. B; BOHNER, T.O.L. Cheia, enchente, inundação e a minimização dos seus impactos sob o olhar da educação ambiental. Revista Eletrônica em Gestão, Educação e Tecnologia Ambiental REGET/UFSM (e-ISSN: 2236-1170), v(5), n5, p. 648 - 652, 2012.

CANHOLI, A. P. Drenagem Urbana e Controle de Enchentes - 2 ${ }^{\mathrm{a}}$ Ed. 2015

LEITE, M. E; PEREIRA, A. M. Metamorfose do espaço intra-urbano de Montes Claros/MG. Montes Claros: Editora da Unimontes, 2008

LEOPOLD, L.B; CLARKE, F.S; HANSHAW, B. et al.. A procedure for evaluating environmental impact. Washington: U. S. Geological Survey, 1971. 13p. (circular 645) 
MOTA, S; AQUINO, M.D. Proposta de uma matriz para avaliação de impactos ambientais. VI Simpósio Ítalo Brasileiro de Engenharia Sanitária e Ambiental, 2002.

OLIVEIRA, F.F.G; MEDEIROS,W.D.A. Bases teórico-conceituais de métodos para avaliação de impactos ambientais em eia/rima. Mercator - Revista de Geografia da UFC, ano 06, número 11,2007

RESCK, D.V.S. Manejo e Conservação do Solo em Microbacias Hidrográficas. Planaltina: Embrapa-CPAC, 1992. 17p. (EMBRAPA - CPAC. Documentos, 40).

TUCCI, Carlos E. M. Água no meio urbano. In: Água Doce. 1997.

TUCCI, Carlos E. M. Gestão de Águas Pluviais Urbanas/- Ministério das Cidades - Global Water Partnership - Wolrd Bank - Unesco 2005

TUCCI, C.E.M. Inundações Urbanas. Porto Alegre: ABRH/RHAMA. p.393,1999.

Trabalho enviado em outubro de 2015 Trabalho aceito em julho de 2016 
Quadro 2 - Matriz de Impactos Sub-bacia do Córrego Vargem Grande em Montes Claros/MG

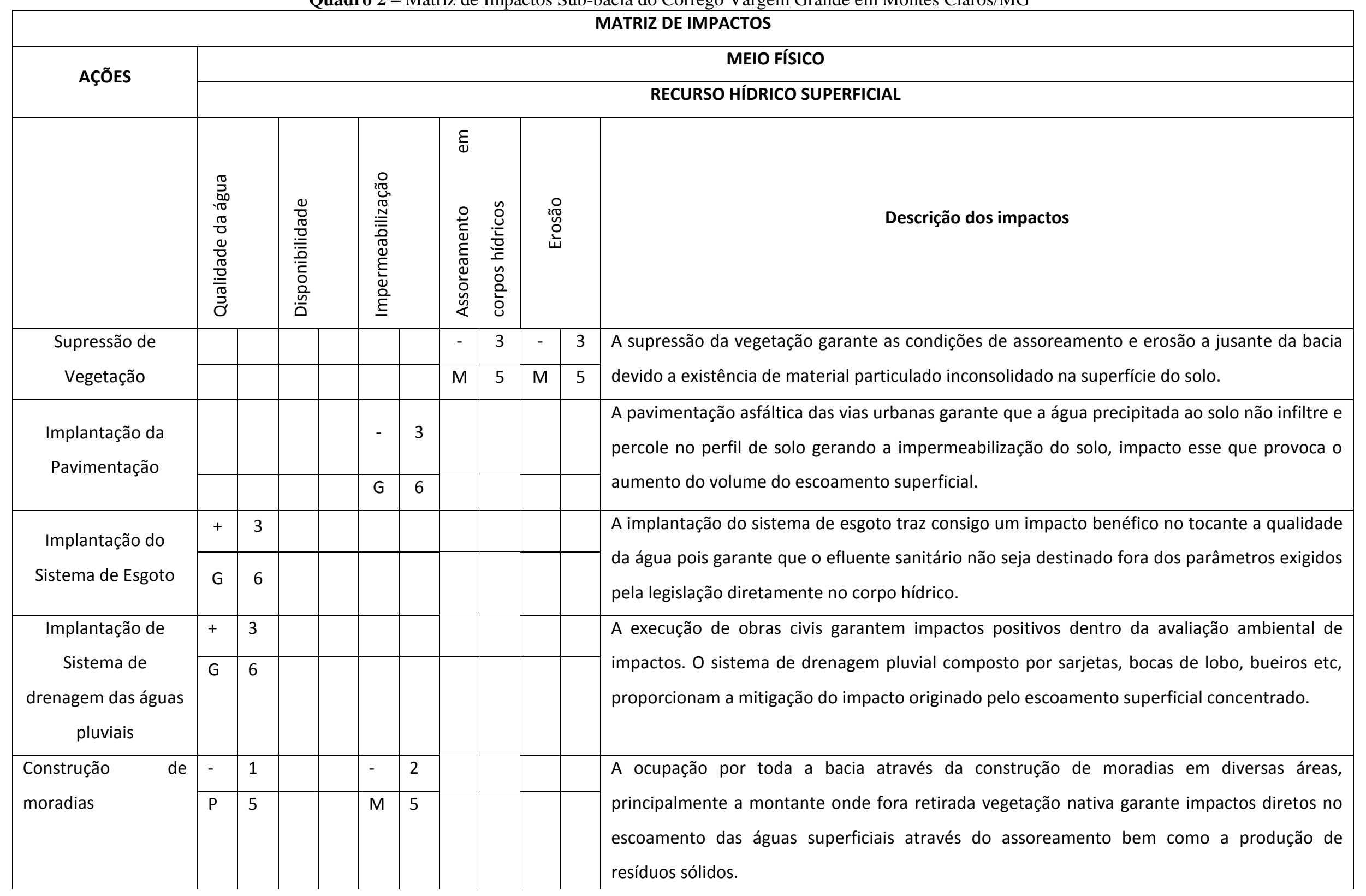




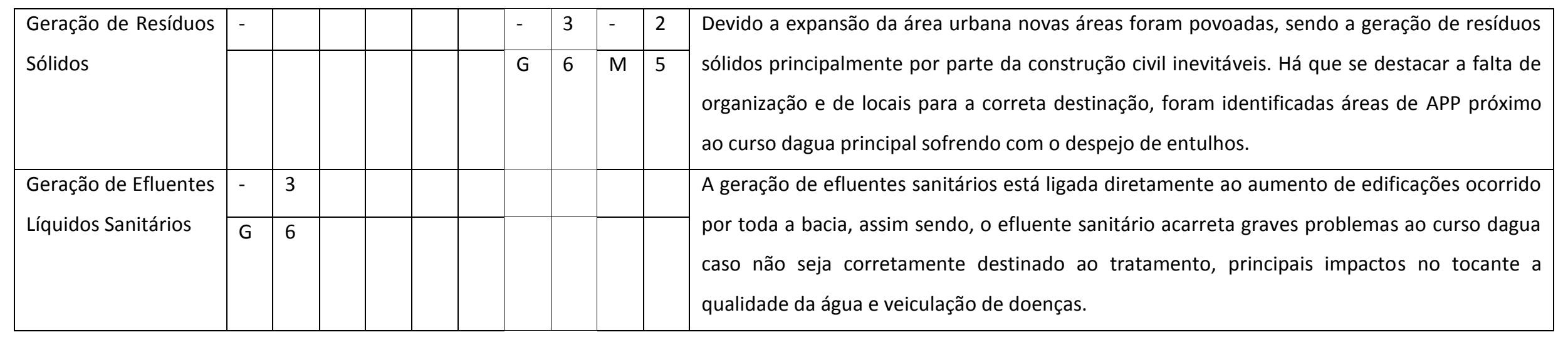

